Boise State University

ScholarWorks

Criminal Justice Faculty Publications and

Presentations

Department of Criminal Justice

$1-1-2011$

\title{
ADHD and Criminality: A Primer on the Genetic, Neurobiological, Evolutionary, and Treatment Literature for Criminologists
}

Catrina M. Schilling

Boise State University

Anthony Walsh

Boise State University

Ilhong Yun

Boise State University

\section{(c) $(1) \Theta \Theta$}

This is an author-produced, peer-reviewed version of this article. (C) 2009, Elsevier. Licensed under the Creative Commons AttributionNonCommercial-NoDerivatives 4.0 International License (https://creativecommons.org/licenses/by-nc-nd/4.0/). The final, definitive version of this document can be found online at Journal of Criminal Justice, doi: 10.1016/j.jcrimjus.2010.11.001 
NOTICE: This is the author's version of a work accepted for publication by Elsevier. Changes resulting from the publishing process,

including peer review, editing, corrections, structural formatting and other quality control mechanisms, may not be reflected in this

document. Changes may have been made to this work since it was submitted for publication. The definitive version has been published in Criminal Justice, Volume 39, Issue 1, 2011, DOI: 10.1016/j.jcrimjus.2010.11.001

\title{
ADHD and Criminality: A Primer on the Genetic, Neurobiological, Evolutionary, and Treatment Literature for Criminologists
}

\author{
Catrina M. Schilling, Anthony Walsh, and Ilhong Yun \\ Boise State University
}

\begin{abstract}
This paper is a primer on ADHD and its major comorbidities for criminologists unfamiliar with the genetic, neurobiological, and evolutionary literature on the subject. With Unnerver, Cullen \& Pratt (2003) we are surprised that criminologists do not pay sufficient attention to a disorder that is found at rates in prisons around the world greatly exceeding in prevalence in the general population. Unnerver, Cullen \& Pratt (2003) believe that it is because ADHD research has been carried out primarily by biomedical researchers and that criminologists tend to shy away from anything smacking of biology. We believe that the special expertise of criminologists in uncovering environmental correlates of antisocial behavior can benefit biomedical research and that biomedical research can assist criminologists in uncovering the individual-level correlates of antisocial behavior.
\end{abstract}

\section{Introduction}

Attention-deficit/hyperactivity disorder (ADHD) is the most commonly diagnosed behavioral disorder of young children and adolescents. There is an abundance of research that identifies a strong and robust relationship between ADHD and delinquent and criminal behavior (Gordon \& Moore, 2005; Pratt et al., 2002. A review of 100 studies (Ellis \& Walsh, 2000) found that 99 of them reported a positive relationship between ADHD and various antisocial behaviors - violent and property crimes, delinquency, drug abuse. Individuals diagnosed with ADHD are consistently found to be overrepresented in juvenile detention centers, jails, and prisons worldwide (Rösler Rosler et al., 2004), and it has been suggested that ADHD may underlie one of criminology's most revered etiological concepts - low self-control (Unnever, Cullen, \& Pratt, 2003). The risk factor for delinquent or criminal behavior is increased for individuals who are comorbid for conduct disorder (CD) and oppositional defiant disorder (ODD) (Comings, 2005). For those who are afflicted with all three conditions, ADHD symptoms usually appear first, followed by ODD symptoms, and then CD.

Gudjonsson and colleague's (2009) review of nine studies of ADHD rates among adult prison inmates using various diagnostic criteria in a number of countries found rates ranging from $24 \%$ to $67 \%$. A German study (Rosler et al, 2004 ) found that $45 \%$ of the inmates had some form of ADHD (there are a number of subtypes) compared to $9.4 \%$ of a control sample. This same study found that $85.5 \%$ of the ADHD inmates were comorbid for alcohol and substance abuse/dependence, and that $30.2 \%$ of them with either definite or possible antisocial personality disorder. Inmates with ADHD also have significantly more prison violations such as verbal and physical aggression, destruction of property, and self-injury (Young et al, 2009). A study of lifetime criminality among 207 white males diagnosed with childhood ADHD and free of CD compared with a control group found that $42 \%$ had been convicted of at least one officially recorded crime by age 38 compared with $14 \%$ of controls (Mannuzza, Klein, \& Moulton, 2008). Thus, even in the absence of CD, ADHD remains a significant risk of criminal behavior.

Criminologists are familiar with ADHD and its symptoms and correlates, although they may not be familiar with its etiology as understood by natural scientists. Unnerver, Cullen \& Pratt (2003:495) point out that ADHD research "has been conducted primarily by psychologists and biomedical researchers with few ties to the field of criminology." They further point out that because ADHD is a major risk factor for antisocial behavior that criminologists must become involved with this research because they can offer insights that would be "theoretically consequential." We agree, and we believe that a review of the ADHD literature most pertinent for criminology is called for. We ask if the condition is a true nosological disorder or a normal variant of a human phenotype that happens to be unsuited to modern social conditions. We also examine current correctional treatment protocols used to ease ADHD symptoms. 


\section{Definitions and Prevalence}

ADHD is defined clinically in the American Psychiatric Association's (APA, 1994) Diagnostic and Statistical Manual of Mental Disorders (DSM-IV) as a disruptive behavior disorder characterized by ongoing inattention and/or hyperactivity-impulsivity occurring in several settings more frequently and severely than is typical for persons in the same stage of development. Three major types of ADHD have been recognized. The first is the predominately inattentive type (unorganized, difficulty following instructions or conversations, easily distracted and forgetful). The second type is the predominantly hyperactive-impulsive type (constantly in motion, restless, impulsive, difficulty in following directions). The third type is the combined type in which the symptoms of the first two types are equally in evidence. For the sake of brevity we only concern ourselves with the combined type. The identified symptoms vary widely in their severity and frequency of occurrence and most healthy children will sometimes manifest them. However, they cluster together to form a syndrome in ADHD children and are chronic and more severe than simple childish high spirits. ${ }^{1}$ The ADHD traits, especially the combined type, associated with criminality include impairment of executive functions, low self- control, low arousal levels, difficulty with peers, frequent disruptive behavior, academic underachievement, risk taking, proneness to extreme boredom, and even "fledgling psychopathy (DeLisi et al, 2010). According to the DSM-IV, 3\% to 7\% of children are diagnosed with ADHD, but there is little consensus on these figures, with some estimates as high as $10 \%$.

\section{The Genetics and Neurobiology of ADHD}

The precise etiology of ADHD is not known, but numerous family, twin, and adoption studies reveal a strong genetic component. Heritability estimates for ADHD average about .80 and are consistently found regardless of whether it is considered a categorical or continuous trait (Bobb et al., 2006). Heritability studies show only that genes are is involved, but not which genes; molecular genetics is required to do that. Molecular genetic studies show ADHD to be highly polygenic, with at least 50 genes with small to moderate effects being involved (Comings et al, 2005). The highly polygenic nature of ADHD probably explains why it is so clinically heterogeneous and why it is linked to many other problems such as CD, ODD, substance abuse, pathological gambling, and antisocial behavior in general.

The hunt for candidate genes implicated in any disorder involves looking at genetic polymorphisms. ${ }^{2}$ It is estimated that about $85 \%$ of genetic causes of most behavioral disorders are attributable to single nucleotide polymorphisms (SNP)s, the most frequently occurring polymorphism (Plomin et al., 2001). The other types are often lumped together as VNTRs (variable number of tandem repeats) that consist of sections of DNA repeated a different number of times in different alleles. We limit ourselves to the three polymorphisms that meta-analyses (Bobb et al., 2006; Gizer, Ficks, \& Waldman, 2009) have shown to be most replicated in ADHD genetic studies and which are also implicated in criminal and other forms of antisocial behavior: the dopamine receptor D4 (DRD4), the dopamine transporter (DAT1), and the serotonin transporter (5-HTT). We emphasize that genes associated with complex disorders such as ADHD are likely to have low penetrance and thus many carriers will not develop the disorder.

Whatever the genes associated with ADHD may be, they manufacture neurotransmitter, receptor, transporter, or enzymes. These substances are utilized in all parts of the brain, but the most salient part for understanding ADHD is the prefrontal cortex (PFC), "the most uniquely human of all brain structures" (Goldberg, 2001:2). This vital area has extensive connections with other cortical regions as well as with deep structures in the limbic system. Because of its many connections with other brain areas, it is generally considered to play the major integrative, as well as the major supervisory role in the brain, and is vital to the forming of moral judgments, mediating affect, and for social cognition (Romain \& Reynolds, 2005). It is the last part of the brain to mature (to become fully myelinated), which typically does not occur until mid-adolescence-early adulthood (Sowell et al, 2004). ${ }^{4}$ Not coincidentally, it is at this time that many ADHD symptoms, especially impulsiveness, tend to subside, although about 90 percent of ADHD individuals continue to exhibit some symptoms into adulthood (Willoughby, 2003).

ADHD is a disorder of neurological regulation and underarousal, making the PFC a key focus of neuroscientists researching ADHD. The PFC provides us with knowledge about how others see and think about us, thus moving us to adjust our behavior to consider their needs, concerns, and expectations. These PFC functions are collectively referred to as executive functions (Tripp \& Wickens, 2009), and are clearly involved in prosocial behavior if functioning normally. Meta-analyses of brain imaging studies show that reductions in the gray matter volume in the 
NOTICE: This is the author's version of a work accepted for publication by Elsevier. Changes resulting from the publishing process, including peer review, editing, corrections, structural formatting and other quality control mechanisms, may not be reflected in this document. Changes may have been made to this work since it was submitted for publication. The definitive version has been published in Criminal Justice, Volume 39, Issue 1, 2011, DOI: 10.1016/i.icrimius.2010.11.001

both left and right cortices of the PFC are the most robust and consistent brain region deficits associated with ADHD (Valera et al., 2007). The PFC requires optimal levels of the neurotransmitters dopamine (DA) and norepinephrine (NE) to function well. Too little DA and NE and we become drowsy, bored, or fatigued, too much and we are stressed, either of which impairs PFC functioning. In short: "Imaging studies have demonstrated that patients with ADHD have alterations in PFC circuits and demonstrate weaker PFC activation while trying to regulate attention and behavior" (Arnsten, 2009:22).

\section{ADHD and Reinforcement Sensitivity Theory}

Dopamine (DA) and serotonin (5-Hydroxytryptamine [5-HT]) are central to the major neurobiological theory focusing on the emotional expression or suppression of behavior known as Reinforcement sensitivity theory (RST) (Cooper, Perkins, \& Corr, 2007) or as reward dominance theory in biosocial criminology (Cauffman, Steinberg, \& Piquero, 2005). RST posits three interacting systems of emotional regulation located within separate brain circuits and relying on different neurotransmitters: the behavioral activating (or approach) system (BAS), the behavioral inhibition system (BIS), and the fight-flight-freeze system (FFFS). The BAS and BIS are part of the limbic system with extension projections into the lobes of the PFC, and the FFFS is part of the autonomic nervous system (ANS). The BAS is sensitive to signals of reward from both conditioned (e.g., alcohol, gambling) and unconditioned (e.g., food, sex) appetitive stimuli. The BIS is sensitive to conditioned (e.g., violations of social rules) and unconditioned (e.g., heights, snarling creatures) threats of punishment (Corr, 2004).

The BAS is primarily associated with DA and with mesolimbic system structures such as the nucleus accumbens, a structure rich in neurons that produce and respond to DA (Day \& Carelli, 2007). The BIS is associated with 5-HT and with limbic system structures such as the hippocampus and the amygdala that feed their memory circuits into the PFC (Goldsmith \& Davidson, 2004). ${ }^{3}$ DA is a powerful regulator of behavioral and cognitive functions, thus any aspect of reduced dopaminergic functioning results in behavioral and cognitive dysregulation. Both the 7 repeat (7R) allele of the DRD4 and the 10 repeat (10R) allele of the DAT1 are associated with reduced dopaminergic functioning (Mill et al., 2006).

The DRD4-7 Repeat Allele The DRD4 gene is one of the most polymorphic genes known, coming in long and short forms of 48 bases that repeat between 2 and 11 times (Ding et al., 2002). The shorter the repeat the more responsive the brain is to DA; the longer the repeat the less responsive it is. Worldwide studies find that $65.1 \%$ of individuals have the $4 \mathrm{R}$ allele, $19.2 \%$ have the $7 \mathrm{R}, 8.8 \%$ the $2 \mathrm{R}$, and the remaining 6.9 percent having one of the other rare repeats. Individuals with two or three repeats tend to be over stimulated by events that most people (the 4Rs) find optimally stimulating and thus they seek to tone them down or withdraw. Individuals the $7 \mathrm{R}$ are suboptimally aroused by those same events. Suboptimal arousal is subjectively experienced as boredom, and bored people seek to raise the level of stimuli to alleviate it, which sometimes results in criminal or other forms of antisocial behavior.

DAT1-10R Allele DAT1 is a gene that largely determines the magnitude and the duration of synaptic DA signaling by transporting DA from the synaptic cleft back into the presynaptic knob for repackaging and reuse after it has excited downstream neurons. The DAT1 gene contains 7, 9, 10, and 11 repeat alleles, with the 9R and 10R being most common (Guo et al, 2007). The 10R is more efficient in the reuptake process than the other major repeat (9R), which implies less DA in the synaptic cleft available for activation (Miller-Butterworth et al., 2008). Because DA activates pleasure centers in the nucleus accumbens, its too-rapid clearing from the synaptic cleft leads the person to seek out pleasures, legal or illegal, that raise DA to desirable levels.

A number of studies have looked at the relationship of the DAT1-10R on risky sensation-seeking and antisocial behavior. For instance, Guo and his colleagues (2007) found that males who were homozygous for the 10R allele (10R/10R) had 80 to 100 percent (depending on age category) more sex partners than males who were homozygous for the $9 \mathrm{R}$ version. Another study found that the DAT1-10R allele was significantly related to number of sex partners and antisocial behavior among a large sample of males between the ages of 18 and 26 (Beaver, Wright, \& Walsh, 2008). Of course, we cannot consider an allele as common as the $10 \mathrm{R}$ to be a defective one. It is more reasonable to consider the 9R a "conservative" allele that confers lessened motivation to seek pleasure (Guo et al, 2007). 
Although the association of the DRD4-7R allele with ADHD is the most replicated association in molecular genetic studies of ADHD (Bobb et al., 2006), there have been some failures to replicate, indicating that gene $\mathrm{x}$ gene interactions (GxG) should be considered. Carrasco et al's (2006) GxG study found that neither the DRD4-7R nor the DAT1-10R polymorphisms had a statistically significant effect on ADHD, but individuals who possessed both polymorphisms were significantly more likely to be diagnosed with ADHD (odds ratio $=12.7$ ) than subjects possessing neither or only one of these alleles.

5-HTT Gene If DA is the accelerator of behavior in the RST model, 5-HT is the brake. The 5-HT equivalent of the DAT1 is the 5-HTT that transports 5-HT back to the vesicles in the presynaptic knob. The 5-HTT gene has a polymorphism in its promoter region (5-HTTLPR) leading to short (S) and long (L) variants. The short variant results in reduced transcription of the transporter protein leading to slower reuptake of 5-HT leaving more of it available to excite or inhibit downstream neurons. The long variant, especially the homozygous $(\mathrm{L} / \mathrm{L})$ genotype, is associated with ADHD because this variant rapidly clears 5-HT from the synapse resulting in its reduced availability of the behavior-inhibiting "brake" (Wallis et al, 2008). The BAS/BIS motivating/inhibiting system has been considered conceptually to be modern neuroscience's analog of the Freudian Id and Superego, with BAS-BIS balance being the Ego (Walsh, 2009).

The final dimension of RST is the FFFS. Because part of the FFFS system includes the amygdala and hippocampus, the BIS and the FFFS may be thought of as a single integrated inhibition system, the BIS in terms of conditioned (anxiety/guilt) inhibitors and the FFFS of both conditioned and unconditioned (fear) inhibitors. Anxiety, guilt, and fear all lead to avoidance behavior in the face of punishment cues. Although the FFFS is part of the autonomic nervous system (ANS), Jeffrey Gray, the originator of RST, coined the phrase to distinguish the ANS's fight/flight function from its "housekeeping" functions such as maintaining homeostasis in the viscera (Gray, \& McNaughton, 2000). The ANS has two branches: the sympathetic and parasympathetic systems. When an organism perceives a threat, its amygdala-associated neural networks send signals to the sympathetic branch to mobilize the body for vigorous action ("fight or flight"). The parasympathetic system restores the body to homeostasis after the organism perceives the threat to be over.

If ADHD behavior is in part a function of a relatively unregulated seeking of pleasure due to suboptimal arousal, then individuals with it should display hyporeactivity of the ANS, particularly if they are comorbid for CD or ODD, because a sluggish ANS implies a low level of fear, which is useful to a criminal (Ortiz \& Raine, 2004). ANS arousal is measured primarily by electrodermal responses known as skin conductance (how well amplified electric signals from electrodes attached to the fingers is conducted; the greater the conductivity the greater the arousal) and heart rate (the higher the rate the higher the arousal). Studies have consistently shown that ADHD, especially ADHD+CD or ADHD+ODD individuals display low ANS arousal (Crowell et al, 2006; Posthumus et al, 2009). A large literature also exists attesting to a robust association between low ANS arousal and persistent delinquent and criminal behavior (reviewed in Scarpa \& Raine, 2003).

\section{ADHD, CD, and ODD Comorbidity}

In addition to placing individuals at increased risk for antisocial behavior, delinquents with ADHD are more likely than non-ADHD delinquents to persist in their offending as adults. This probability rises dramatically for ADHD individuals comorbid for CD (Comings, et al., 2005). Lynam (196:209) has stated that the ADHD+CD combination is a "particularly virulent strain ....best described as fledgling psychopathy." CD is defined as persistent serious antisocial acts such as assaulting, stealing, setting fires, bullying, cruelty to animals, vandalism, that are excessive for a child's developmental stage, and it is considered one of the most stable diagnoses in psychiatry (Comings et al, 2005). ADHD and CD are found to co-occur in about 50\% of cases in most clinical and epidemiological studies (Waschbusch et al. 2002). Conduct disorder has an onset at around five years of age. It remains at a steady rate for girls (about $0.8 \%$ of all girls) and rises to about $2.8 \%$ at age 15 , but rises steadily in boys from about $2.1 \%$ at age five to about 5.5\% at age 15 (Maughan et al., 2004). CD is also a neurological disorder with substantial polygenic effects with heritability estimates ranging between .27 and .78 (Coolidge, Thede, \& Young, 2000).

The comorbidity of ADHD with many other disorders strongly suggests that epistasis (the interaction of genes) and pleiotropy (the influence of a single gene on more than one phenotypic trait) are involved as well as genetic heterogeneity (Wallis et al., 2008). The odds of inheriting alleles for comorbid disorders is determined by genetic linkage studies and is quantified by LOD (log of the odds ratio) scores. The genetic logic is that each time the sex 
NOTICE: This is the author's version of a work accepted for publication by Elsevier. Changes resulting from the publishing process, including peer review, editing, corrections, structural formatting and other quality control mechanisms, may not be reflected in this document. Changes may have been made to this work since it was submitted for publication. The definitive version has been published in Criminal Justice, Volume 39, Issue 1, 2011, DOI: 10.1016/i.jcrimius.2010.11.001

cells segregate during meiosis the genes on the chromosomes are not transmitted to the daughter cell with fidelity. The closer two or more alleles are together on a chromosomal locus the greater the odds that they will be transmitted together. A LOD score of 3 is considered the minimal standard of evidence for linkage; i.e., the likelihood that two genes have not separated during meiosis. A LOD of 3 means the hypothesis that the genetic markers are linked is 1,000 times as likely as the null hypothesis that they are not. This value is chosen because the base-10 logarithm of 1,000 is $3\left(10^{3}=1,000\right.$; so $\left.\log _{10} \times 1,000=3\right)$. In one study of 616 subjects, the LOD score for ADHD+CD was 5.34 , for $\mathrm{ODD}+\mathrm{CD}$ it was 6.68 , and for $\mathrm{ODD}+\mathrm{ADHD}$ it was 14.19 , indicating very strong genetic linkages for these syndromes (Jain et al., 2006). ${ }^{5}$

Many of the cognitive and temperamental symptoms of CD and ADHD children are similar. CD children tend to score in the low-normal or borderline range of intelligence, are most likely to be found in impoverished families, and are significantly more likely than children without CD to have parents diagnosed with antisocial personality disorder (ASPD) (Sergeant et al, 2003not in references). One of the psychiatric requirements for a diagnosis of ASPD is a childhood diagnosis of CD. Thus, if a parent is diagnosed with ASPD it means that he (almost always a he) was diagnosed with $\mathrm{CD}$ as a child, and if his offspring is also diagnosed with $\mathrm{CD}$, the cross-generation linkage is further suggestive of genetic transmission (Comings et al. 2005).

A number of researchers have offered evidence that ADHD is a product of a deficient BIS and CD is a product of an oversensitive BAS (Levy, 2004; Quay, 1997). This double disability indicates that ADHD+ CD sufferers are inclined to seek high levels of stimulation because of an oversensitive BAS, and then their faulty BIS hampers them in putting a stop to their search for pleasurable stimulation once it is initiated. Lynam (1996:22) describes the trajectory from ADHD + CD to criminality stating that the co-occurrence of ADHD and CD: "[M]ay tax the skills of parents and lead to the adoption of coercive child rearing techniques, which in turn may enhance the risk of antisocial behavior. Entry into school may bring academic failure and increase the child's frustration, which may increase his or her level of aggressive behavior. Finally, the peer rejection associated with hyperactivity may lead to increased social isolation and conflict with peers."

ODD is an earlier appearing and less severe disorder characterized by behaviors such as temper tantrums and lying. Some view ODD as less severe form of CD, while others maintain the distinction between the two but acknowledge that ODD frequently develops into CD. As Lahey and Loeber (1994:144) describe the distinction: "ODD is an enduring pattern of oppositional, irritable, and defiant behavior, whereas $\mathrm{CD}$ is a persistent pattern of more serious violations of the rights of others and social norms." CD and ODD are developmental and hierarchical in that all children who meet the clinical criteria for CD also meet the criteria for ODD, but not all ODD children will develop $\mathrm{CD}$. Factor analyses of the symptoms and behaviors of the two conditions produce two or three factors, with a three factor solution labeled as "ODD," "intermediate CD," and "advanced CD" (Lahey \& Loeber 1994)

Thornberry, Huizinga, \& Loeber's (2004) pyramidal model of offending that focuses on the escalation of seriousness of delinquent acts being committed as boys age provides us with a useful model with which to view the offending patterns of ODD, CD, and ADHD individuals (see figure 1). The model presents three pathways that represent patterns of offending behavior; it says nothing about clinical syndromes but neatly conforms to Lahey \& Loeber's (1994) three factor model. The Authority Conflict pathway is the earliest pathway (starting before age 12) and begins with simple stubborn behavior (ODD), followed by defiance and authority avoidance. Note that the base of the triangle represents the earliest stage and contains the most boys. Some boys move into the second stage (defiance/disobedience), and a few more will move into the authority avoidance stage. At this point some boys progress to one of the other two pathways, but many will go no further than authority avoidance. The Covert pathway starts later and involves minor offenses in stage 1 that become progressively more serious for a few boys who enter stage 3 on this pathway. The covert pathway would consist overwhelmingly of boys who were not diagnosed with ODD or CD, but perhaps with ADHD. The Overt pathway progresses from minor aggressive acts in stage 1 to very serious violent acts in stage 3 . The more seriously involved delinquents in the overt and covert pathways may switch back and forth between violent and property crimes, with the most serious probably fitting the criteria for ADHD + CD comorbidity. 


\section{Environmental Factors}

Even if ADHD is as much as $80 \%$ heritable, this leaves $20 \%$ of the variance in ADHD symptoms associated with environmental factors. The heritability coefficients of CD and ODD, as well as the heritability of other ADHD comorbid conditions, are much less than .80 and thus leaves plenty of causal space for the environment. Genes and environments are not independent entities driving behavior because genes condition the effects of environments and environments condition the expression of genes. Genes rarely if ever directly effect complex behaviors; rather, individuals create and respond to their environments via the constant interplay of genes and environment through the processes of gene-environment interaction $(\mathrm{GxE})$ and gene-environment correlation (rGE). ${ }^{6}$ Failure to incorporate appropriate environmental risk factors may account for some of the inconsistent findings in biomedical research, and it is here that criminologists can make their contributions felt (see Vaughn et al., 2009).

GxE involves different phenotypes responding to environments in different ways because of genetic biases and is captured by the saying "the heat that melts the butter hardens the egg." The same "heat" (environment) that provides a fearless and impulsive child (the "egg" genotype) opportunities for antisocial behavior does not for a fearful and less impulsive child (the "butter" genotype). The concept of rGE avers that genotypes and the environments they encounter are not random with respect to one another and that genetic factors influence complex psychosocial traits by influencing the range of individuals' effective experiences (Moffitt, 2005). Because genes affect differential exposure to environmental risks via active rGE and differential susceptibility to environmental risks via GxE, both processes are always operating and difficult to untangle. In other words, people self-select themselves into different environments on the basis of their genetic preferences when they are able (rGE), and because they self-select a particular environment they will be more susceptible to its influence (GxE) than will those there by happenstance. Once in contact with an environment inhabited by antisocial others, the environment may have unique causal effects.

Environmental features identified as playing a role in the etiology of ADHD are fetal exposure to noxious substances (particularly maternal smoking during pregnancy), perinatal complications, and head trauma (Durston, 2003). Factors such as family and school experiences or peer pressure do not to have any causal impact on ADHD, although they tend to exacerbate its symptoms (Coolidge, Thede, \& Young, 2000). A number of studies have shown that while non-biological (everything not transmitted in the DNA is considered environmental) environmental factors alone cannot induce ADHD, they can lead to ADHD comorbidity with ODD and CD, and hence to delinquent and criminal behavior (Ficks \& Waldman, 2009). We have already noted Lynam's (1996) description of how the behavior of ADHD children tax parental skills and often lead to the type of coercive parenting that often leads to ODD and CD. This is an example of evocative rGE in that the child's behavior evokes reactions from parents that magnify the child's antisocial phenotype. In other words, while there is no dispute that abused children evidence higher rates of ADHD and comorbid disorders than non-abused children the "causal" direction is far from certain, particularly since ADHD children tend to have parents who exhibit at least some of the symptoms of ADHD themselves (Ficks \& Waldman, 2009).

Moffitt and her colleagues (1994) propose that verbal deficits are what place children at risk for CD. Neurological evidence suggests that the left frontal lobes contain the mechanisms by which children process their parents' instructions that become their internalized basis of self-control. Children with deficits in these mechanisms fail to profit from their parent's verbal instructions and tend to develop a present-oriented and impulsive cognitive style. Lacking normal ability to connect abstract verbal commands with their own concrete behavior, such children may have to learn lesson through the more painful process of trial and error and may thus experience more frequent punishments for their lack of compliance with instructions. As Moffitt et al., (1994:296) put it: "Children who have difficulty expressing themselves and remembering information are significantly handicapped. Dysfunctional communication between child and his parents, peers, and teachers may be one of the most critical factors for childhood conduct problems that grow into persistent antisocial behavior in young adulthood."

\section{Gene/Culture Co-Evolution and ADHD}

The relatively high rate of ADHD means that the genes underlying it have survived natural selection because they conferred some benefits in evolutionary environments even if they do not in evolutionarily novel classroom and work environments (Bjorklund \& Pellegrini, 2000). There is strong evidence that the DRD4-7R allele, the most robust genetic correlate of ADHD, is a young variant that arose about 40,000 years ago and has been positively 
NOTICE: This is the author's version of a work accepted for publication by Elsevier. Changes resulting from the publishing process, including peer review, editing, corrections, structural formatting and other quality control mechanisms, may not be reflected in this document. Changes may have been made to this work since it was submitted for publication. The definitive version has been published in Criminal Justice, Volume 39, Issue 1, 2011, DOI: 10.1016/i.icrimius.2010.11.001

selected for (reviewed in Arcos-Burgos \& Acosta, 2007). Positive selection means that behaviors underlain by the genes in question have had some positive effect on the bearer's survival and reproductive success. This does not mean that the full ADHD phenotype is an adaptation. It only suggests that some endophenotypes (energetic, unpredictable, novelty seeking) of ADHD may have been selectively adaptive, not all of them. ADHD children often show neurological deficits, but ADHD children who also carry the DRD4 -7R do not show these deficits (Harpending \& Cochran, 2002). Another study comparing ADHD children with and without the 7R found that children with the allele had better cognitive performance and better prognoses for long-term outcomes than ADHD children without it, suggesting that the: "allele may be associated with a more benign form of the disorder" (Gornick et al., 2007:379). This again shows the heterogeneity, and hence the polygenic nature of ADHD.

A study of 2,320 individuals from 39 different racial/ethnic groups found that the percentage of $7 \mathrm{R}$ version of the DRD4 gene ranged from near zero in populations that have remained in the same geographic region for the last 30,000 years (e.g., Han Chinese, Yemeni Jews) to an average of $63 \%$ in six migratory populations of South American Indians. (Ding et al, 2002NIR). Ding and his colleagues (2002) found the correlation between percentage of 7Rs in a population and geographic distance from the original parent population to be an impressive 0.85 . In evolutionary times ADHD-like behaviors such as restless boldness and curiosity meant exploring beyond known boundaries and would have made such individuals valuable to a band roaming the Savannah - the individual took the risks and the group reaped the benefits.

Williams and Taylor (2006) offer an evolutionary model of ADHD based on the DRD4-7R allele using computer simulations to explore the possible value of unpredictable and novelty seeking behavior in hunter-gatherer environments. They hypothesized that the restlessness and impulsiveness associated with the DRD4-7R allele prompted increased exploration of new behaviors and new territories that enhanced the fitness of those carrying it, and of the group as a whole. Their simulations were supportive of their model. We would expect individuals in groups that elect to migrate from the parent population and explore the greater world to exhibit a greater need for excitement than the average person in the parent population. ${ }^{7}$ To the extent that the need is a function of the $7 \mathrm{R}$ allele it should be well represented among groups with a reputation for boldness, irritableness, boredom-proneness, and fierceness. Commenting on the 7R's variable distribution around the world, Harpending and Cochran (2002:12) state: "It is probably no accident that two of the best known ethnographies of the twentieth century are titled 'The Harmless People,' about the !Kung who have few or no 7R alleles, and the 'Fierce People,' about the Yanomamo with a high frequency of 7R."

Thom Hartman's (2000) hunter versus farmer theory of ADHD also asserts that many of the sub-traits of ADHD such as impulsivity and novelty-seeking were assets when our ancestors were nomadic hunter-gatherers. Hartman theorizes that good hunters were hyper-vigilant to all incoming stimuli, continually monitoring the environment, flexible in their strategies and able to respond immediately to new sights and sounds. In today's classroom and work environments we call this trait "distractibility." Impulsivity also allowed a hunter to rapidly identify and seize opportunities without taking time to plan and consider. With the advent of agricultural and industrial modes of life, different traits that Hartman called "farmer" traits such as prolonged and purposeful linear thinking and focusing on tasks until they are completed became more socially useful. Today the hunter phenotype possessing some ADHD traits without $\mathrm{CD}$ comorbidity may become firefighters and police officers, while the farmer phenotype prefers the quiet plodding cerebral lifestyles of the accountant or computer analyst. Hartman gives a number of examples of how many of the symptoms of ADHD would make a person a better hunter in prehistoric times but which are largely maladaptive and disvalued in today's "farmer's" world.

Eisenberg and his colleagues (2008) tested the theory using data from the Ariaal tribe of Kenya. This tribe is split in two groups some 35 years ago, with some members retaining their traditional nomadic life and the others settling down to an agricultural life. Both factions of the tribe were tested for the DRD4-7R allele with approximately $19.4 \%$ of each faction carrying it. The study found that the nomadic "hunter" members with the allele were generally healthier than those without it, while among the "farmer" members, those with the allele were generally less healthy. In other words, there was a GxE interaction such that the DRD4-7R allele conferred an advantage in one environments and a disadvantage in another, just as the hunter v. farmer hypothesis predicts. Eisenberg et al. (2008: 6) note that the ADHD-like traits conferred by the DRD4-7R would allow "nomadic children to more readily learn effectively in a dynamic [non-school] environment, while the same attention span interferes with classroom learning." They also note that the allele is advantageous for warrior with "a reputation for unpredictable behaviour that inspires fear" but less well suited in sedentary environments where predictability and bonhomie are valued. 
NOTICE: This is the author's version of a work accepted for publication by Elsevier. Changes resulting from the publishing process, including peer review, editing, corrections, structural formatting and other quality control mechanisms, may not be reflected in this document. Changes may have been made to this work since it was submitted for publication. The definitive version has been published in Criminal Justice, Volume 39, Issue 1, 2011, DOI: 10.1016/i.icrimius.2010.11.001

Eisenberg et al. (2008) noted that the emergence of the 7R mutation roughly coincided with the time in which the first signs of rudimentary complex horticultural/agricultural societies began to emerge, and with the time in which humans were exploring and expanding widely around the planet. This observation calls on the concept of geneculture coevolution, which avers that nature (genes) and nurture (cultural learning) constitute a fully integrated feedback system. Both genes and culture are information transmission devices, the former laying the foundation (the capacity) for the latter, and the latter then influencing the former (what polymorphisms are useful in this culture at this time). In other words, if an allele that facilitates a novel trait or behavior emerges that just happens to be culturally useful, those displaying the trait or behavior will be advantaged in terms of securing resources and mates. Using sophisticated technology, Hawks et al. (2007) show that the rate of genomic change has been about100 times greater over the last 40,000 years than it was during the five-million-year long Pleistocene. They attributed this to the greater challenges posed by living in larger and larger social groups: "[T]he rapid cultural evolution during the Late Pleistocene created vastly more opportunities for further genetic changes, not fewer, as new avenues emerged for communication, social interaction, and creativity" (Hawks et al., 2007: 2075).

\section{ADHD Treatment}

Neurological deficits associated with ADHD that get its victims into trouble include suboptimal arousal and frontal lobe dysfunction that show up in EEG patterns of under-arousal. Slow brain waves are subjectively experienced as boredom, which motivates the person to seek or create environments containing more excitement. This problem can be normalized by administering certain drugs, which remain the mainstay of ADHD treatment. The efficacy of early pharmacotherapeutic approaches to calming ADHD individuals gave researchers their first clues to the underlying neurochemical basis for the disorder (Durston, 2003).

The most frequently prescribed drugs for ADHD are methylphenidate-based stimulants such as Ritalin and Concerta (Gilbert et al., 2006). These drugs work as DA agonists by preventing DA synaptic reuptake by occupying the DA transporters, thus increasing DA availability in the PFC and certain subcortical areas associated with reward and punishment. Stimulant drugs have a calming or normalizing affect on suboptimally aroused individuals by raising the activity of the brain's sensory mechanisms to normal levels. This relieves feelings of boredom because the brain is now able to be more attentive to features of the environment that it could not previously capture. When on medication ADHD children are less disruptive, become less obnoxious to peers, and can focus more on schoolwork. Of course, stimulant drugs would have exactly the opposite effect on non-ADHD individuals (Applebaum, 2009).

The issue of treatment with stimulant drugs in correctional settings is a contentious one. Some psychiatrists favor its use while acknowledging the drawbacks, while others believe that the negatives in correctional settings outweigh the undoubted positive benefits of the medication. The high prevalence of substance abusers in prisons, the high potential for the misuse of prescribed drugs, the intimidation of weaker ADHD patients to surrender their drugs, and a number of security and cost issues leads Kathryn Burns (2009) to assert that stimulant medications should never be used in prison settings. On the other hand, Kenneth Applebaum (2009) believes that there is a real place for these effective medications, but believes that they should be prescribed only after the failure of one of the non-stimulant alternatives.

An alternative to methylphenidate-based stimulants is the non-stimulant atomoxetine. Atomoxetime is a $\mathrm{NE}$ reuptake inhibitor that increases both NE activity (and also facilitates DA activity) in the PFC. Both stimulant and non-stimulant drugs have been shown to increase cortical attention and facilitation with stimulant medication working better for some people and non-stimulants for others in reducing ADHD symptoms (Gilbert et al., 2006). Nevertheless, many correctional facilities continue to rely only on psychosocial treatment for ADHD.

Psychosocial interventions play an important role in supplementing pharmacological treatment in community settings. Pharmacological treatment is viewed as necessary to stabilize the brain, and once stabilized psychosocial counseling can help to train ADHD individuals to cope with the problems associated with the condition and to prevent exacerbation of symptoms. Reviews of this literature tend to show positive additional outcomes when medication is augmented by psychosocial therapy (Toplak et al, 2008). In prison settings, however, cognitive behavioral therapy (CBT) generally has to carry the burden alone. 
CBT is currently the preferred psychosocial intervention in most correctional settings (Sharp, 2006). Linden (2006) reviewed a number of neuroimaging studies that assessed the effects on the human brain of CBT compared with the effects of pharmacological treatment for such maladies as depression and obsessive compulsive disorder. Both types of treatment are found to decrease activity in areas of the brain associated with these problems to the same extent "indicating commonalities in the biological mechanisms of psycho- and pharmacotherapy" (Linden 2006:528). The malleable human brain functions analogously to muscles in that its pathways can be strengthened by use. Because these studies were based on community samples of individuals who actively sought out and cooperated with treatment, which is something that is not typical of criminal populations, they cannot be generalized to correctional populations. Of course, treatment concerns are of less importance to criminologists than are etiological issues. Suffice to say that ADHD is not a hopeless pathology that leads to inevitable criminality, particularly when CD is not present, and that it can be managed with treatment.

\section{Conclusion}

This review has been aimed at familiarizing criminologists with the genetic, neurological, evolutionary, and treatment literature on ADHD. It is of necessity extremely brief, but we believe that it focuses on the main issues and research findings about this disorder. With Unnever, Cullen, and Pratt (2003), we believe that ADHD has been much neglected by criminologists. This neglect is surprising given that ADHD individuals are present in correctional populations at rates exceeding their prevalence in the general population by at least three to four times, which increases even further for ADHD+CD individuals. We are led to wonder how many times criminologists have looked at the effects of substance abuse, sensation-seeking, or self-control on criminal or delinquent behavior without considering that all of these things may be endophenotypes of the broader ADHD or ADHD+CD phenotype.

Perhaps we have ignored researching ADHD precisely because such research is dominated by the biomedical sciences from which many criminologists shy away because they still imagine that this is where the ghost of Lombroso still roams restlessly. This is an attitude that must be set aside and written off as something from our discipline's adolescence. We cannot any longer ignore what the biological sciences have to offer our discipline because, as a number of criminologists have recently noted, the biosocial paradigm in criminology is rapidly advancing to the forefront of our discipline (Cooper, Walsh, \& Ellis, 2010; Cullen, 2009; Walsh, 2009; Wright \& Boisvert, 2009).

The advantage that criminologists may gain by being more conversant with ADHD and its comorbidities is that the disorders have robust genetic and neurobiological correlates. That is, biomedical research has provided relatively hard evidence in the form of identified genetic polymorphisms, as well as brain areas of interest identified by the alphabet soup of neuroimaging techniques now available, as opposed to our typical reliance on "soft" questionnairetype data. We now have data sets available to us such as the National Longitudinal Study of Adolescent Health (Add Health) data which contains information on the genotypes of many subjects, and among the genes tested for are the three we have identified in this review as being related to ADHD and CD. On the other hand, biomedical research has often neglected to include a range of known environmental correlates of antisocial behavior and have neglected concepts such as GxE and rGE, and as Unnever, Cullen, and Pratt (2003) pointed out, this is where our expertise can be useful to biomedical research. The cross-fertilization of concepts, methods, and theories from diverse disciplines has been the primary road to progress in other sciences because cross-fertilization breeds hybrid vigor in their resulting offspring.

\section{Endnotes}

1. At least six of nine symptoms of each of the inattentive and hyperactive-impulsive types are required for diagnosis as a combined type.

2. Polymorphism refers to the differences in allelic combinations (an allele is an alternate form of a gene; one inherited maternally and one paternally) that make us different from one another even though we share the same genes. There are three different types of polymorphisms: single nucleotide polymorphisms (SNPs), minisatellites and microsatellites (Altukhov \& Salmenkova, 2002). As the term SNP implies, a difference in just one nucleotide is all that differentiates one allele from another. A nucleotide is one of the four nitrogenous bases (adenine, cytosine, guanine, thymine or uracil) plus a sugar and phosphate backbone that make up DNA and RNA. When we consider that the human genome contains approximately 3 billion base pairs we can appreciate the potential number of polymorphisms it contains. 
NOTICE: This is the author's version of a work accepted for publication by Elsevier. Changes resulting from the publishing process, including peer review, editing, corrections, structural formatting and other quality control mechanisms, may not be reflected in this document. Changes may have been made to this work since it was submitted for publication. The definitive version has been published in Criminal Justice, Volume 39, Issue 1, 2011, DOI: 10.1016/i.icrimius.2010.11.001

3. The amygdala and hippocampus are part of the limbic system, and each is distributed bilaterally. The amygdala's primary function is the storage of "hot" memories associated with the full range of emotions, particularly fear. After the amygdala processes an emotion it directs other brain structures to initiate responses geared to specific situations. The hippocampus is specialized for storing and processing visual and spatial "cold" memories such as facts and events. Connections between the amygdala and hippocampus help to focus the brain on what the organism has learned about responding to the kind of emotional stimuli that has aroused it, thus regulating it with memories of prior experiences

4. Myelin is the fatty substance that coats the neuronal axons and acts as insulation. Myelinated axons allow for speedier transmission of the electric message along the length of the axon. 5. For those interested in how a statistical link is established between a phenotypic outcome and a genetic variant, Guo and Adkins (2008) supply an excellent primer for social scientists.

6. There are three types of rGE. (1) Passive rGE refers the provision of infants of genes that facilitate certain traits and an environment favorable for their expression-genotype and its environment are positively correlated. (2) Evocative rGE refers to the way others in the social environment react to the individual on the basis of his or her behavior and serves to magnify differences among phenotypes. (3) Active rGE refers to people actively seeking of environments compatible with their genetic dispositions. The reactions we evoke from others will help us to determine the environments we will seek. Thus evocative and active rGE feed back on one another.

7. In light of this it is interesting to note what Charles Darwin wrote almost 150 years ago: "Restless men who will not follow any steady occupation - and this relic of barbarism is a great check to civilisation - emigrate to newlysettled countries, where they prove useful pioneers"(1871:172). 


\section{References}

Arcos-Burgos, M. \& M. Acosta (2007). Tuning major gene variants condition human behavior: The anachronism of ADHD. Current Opinion in Genetics and Development, 17: 234-238.

Altukhov, Y. \& E. Salmenkova (2002). DNA polymorphisms in population genetics. Russian Journal of Genetics, 38:1173-1195.

Arnsten, A. (2009). The emerging neurobiology of attention deficit hyperactivity disorder: The key role of the prefrontal cortex. The Journal of Pediatrics, 154:S22-S28.

Applebaum, K. (2009). Attention-deficit hyperactivity disorder in prison: A treatment protocol. The Journal of the American Academy of Psychiatry and Law, 37:45-49.

Beaver, K., J. Wright, \& A. Walsh (2008). A gene-based Evolutionary explanation for the association between criminal involvement and number of sex partners. Biodemography and Social Biology, 54:47-55.

Bjorklund, D. \& A. Pellegrini (2000). Child development and evolutionary psychology. Child Development, 71:1687-1708.

Bobb, A. F. Castellanos, A. Addington \& J. Rapoport (2005). Molecular genetic studies of ADHD: 1991 to 2004, American Journal of Medical Genetics-Neuropsychiatric Genetics, 132:109-125.

Burns, K. (2009). Commentary: The top ten reasons to limit prescription of controlled substances in prison. The Journal of the American Academy of Psychiatry and Law, 37:50-52.

Carrasco, X., P. Rothhammer, M. Moraga , H. Henríquez, R. Chakraborty, F. Aboitiz, \& F. Rothhammer (2006). Genotypic interaction between DRD4 and DAT1 loci is a high risk factor for attention-deficit/hyperactivity disorder in Chilean families. American Journal of Medical genetics (Neuropsychiatric Genetics), 141B:5154.

Cauffman, E., L. Steinberg, \& A. Piquero, A. (2005). Psychological, neuropsychological, and psychophysiological correlates of serious antisocial behavior in adolescence. Criminology, 43, 133-176.

Comings, D., T. Chen, K. Blum, J. Mengucci, S. Blum, \& B. Meshkin (2005). Neurogenic interactions and aberrant behavioral co-morbidity of attention deficit hyperactivity disorder (ADHD): Dispelling myths. Theoretical Biology \& Medical Modeling, 2:50:65.

Cooper, J., A. Walsh, \& L. Ellis (2010). Is Criminology Ripe for a Paradigm Shift? Evidence from a Survey of American Criminologists. Journal of Criminal Justice Education,

Crowell, S., T. Beauchaine, L. Gatzke-Kopp, P Sylvers, H. Mead, \& j. Chipman-Chacon (2006). Autonomic correlates of attention-deficit/hyperactivity disorder and oppositional defiant disorder in preschool children. Journal of Abnormal Psychology, 115-174-178.

Cullen, F. (2009). Foreword to A. Walsh \& K. Beaver, Biosocial Criminology: New directions in theory and research. New York: Routledge.

Darwin, C. (1871). The descent of man, and selection in relation to sex. London: J.Murray.

Day J. \& R. Carelli (2007). The nucleus accumbens and Pavlovian reward learning. The Neuroscientist, 13:148-159.

DeLisi, M., M. Vaughn, K. Beaver, J. Wexler, A. Barth \& J. Fletcher (2010). Fledling psychopathy in the classroom: ADHD subtypes, psychopthy, and reading comprehension in a community sample of adolescents. Youth Violence and Juvenile Justice, doi10.1177/1541204010371932.

Ding, Y., H. Chi, D. Grady, A. Morishima, J. Kidd, K. Kidd, P. Flodman, M. Spence, S. Schuck, J. Swanson, Y. Zhang, \& R. Moyziz (2002). Evidence of positive selection acting at the Human dopamine receptor D4 gene locus. Proceedings of the National Academy of Science, 99:309-314.

Durston, S. (2003). A review of the biological bases of ADHD: What have we learned from imaging studies? Mental Retardation and Developmental Disabilities, 9:184-195.

Eisenberg, D., B. Campbell, P. Gray \& M. Sorenson (2008). Dopamine receptor genetic polymorphisms and body composition in undernourished pastoralists: An exploration of nutrition indices among nomadic and recently settled Ariaal men of northern Kenya. BMC Evolutionary Biology, 8:6-12.

Ficks, C. \& I. Waldman (2009). Gene-environment interactions in attention-deficit/hyperactivity disorder. Current Psychiatry Reports, 11:387-392.

Gilbert, D., K. Ridel, F. Sallee, J. Zhang, T. Lipps \& E. Wassermann (2006). Comparison of the inhibitory and excitatory effects of ADHD medications methylphenidate and atomoxetine on motor cortex. Neuropsychopharmacology, 31: 442-449.

Gizer, I., C. Ficks, \& I Waldman (2009). Candidate gene studies of ADHD: A meta-analytic review. Human Genetics, 126:51-90. 
Goldberg, E. (2001). The executive brain: Frontal lobes and the civilized mind. New York: Oxford University Press.

Goldsmith, H. \& R. Davidson (2004). Disambiguating the components of emotion regulation. Child Development, 75: 361-365.

Gordon, J. \& P. Moore (2005). ADHD among incarcerated youth: An investigation of the congruency with ADHD prevalence and correlates among the general population. American Journal of Criminal Justice, 30:87-97.

Gornick, M., A. Addington, P. Shaw, A. Bobb, W. Sharp, D. Greenstein, S. Arepalli, F. Castellanos, J. \& L. Rapoport (2007). Association of the dopamine receptor D4 (DRD4) gene 7-repeat allele with children with attention-deficit/hyperactivity disorder (ADHD): An update. American Journal of Medical Genetics, 144: 379-383.

Gray, J \& N. McNaughton (2000).The neuropsychology of anxiety: An enquiry into the functions of the septohippocampal system. Oxford: Oxford University Press.

Gua, G. \& D. Adkins (2008). How is a statistical link established between a human outcome and a genetic variant? Sociological Methods and Research, 37:201-226.(no citation)

Gudjonsson, G., J. Sigurddsson, S. Young, A. Newton, \& M. Peersen (2009). Attention deficit hyperactivity disorder (ADHD). How do ADHD symptoms relate to personality among prisoners? Personality and Individual Differences, 47:64:68.

Guo, G., Y. Tong, C-W. Xie, \& L. Lange (2007). Dopamine transporter, gender, and number of sexual partners among young adults. European Journal of Human Genetics, 15:279-287

Harpending, H. \& G. Cochran (2002). In our genes. Proceedings of the National Academy of Science, 99:10-12.

Hartman, T. (2000). Thom Hartmann's Complete Guide to ADD. Nevada City, CA: Underwood.

Hawks, J., E. Wang, G. Cochran, H. Harpending, \& R. Moyzis (2007). Recent acceleration of human adaptive evolution. Proceedings of the National Academy of Science, 104:20753-20758.

Jain M., L. Palacio, F. Castellanos, J. Palacio, D. Pineda, M. Restrepo, J. Muñoz, F. Lopera, D. Wallis, K. Berg, J. Bailey-Wilson, M. Arcos-Burgos \& M. Muenke (2007). Attentiondeficit/hyperactivity disorder and comorbid disruptive behavior disorders: evidence of pleiotropy and new susceptibility loci. Biological Psychiatry, 61:1329-39.

Lahey, B. \& R. Loeber (1994). Framework for a developmental model of oppositional defiant disorder and conduct disorder. In D. Routh (Ed.), Disruptive Behavior Disorders in Childhood, pp.139-180. New York: Plenum.

Levy, F. (2004). Synaptic gating and ADHD: A biological theory of comorbidity of ADHD and anxiety. Neuropsychopharmacology, 29:1589-1596.

Linden, D. (2006). How psychotherapy changes the brain-the contribution of functional neuroimaging. Molecular psychiatry, 11:528-538.

Lynam, D. (1996). Early identification of chronic offenders: Who is the fledgling psychopath? Psychological Bulletin, 120:209-234.

Mannuzza, S., R. Klein, \& J. Moulton (2007). Lifetime criminality among boys with ADHD: A prospective followup study into adulthood using official arrest records. Psychiatry Research, 160:237-246.

Maughan, B., R. Rowe, J. Messer, R. Goodman, \& H. Meltzer (2004). Conduct disorder and oppositional defiant disorder in a national sample: Developmental epidemiology. Journal of Child Psychology and Psychiatry, 43:609-621.

Mill, J., Caspi, A., Williams, B, Craig, I., Taylor, A., Polo-Tomas, M., Berridge, C., Poulton, R. \& Moffitt, T. (2006). Genetic polymorphisms in the dopamine system predict heterogeneity in intelligence and adult prognosis among children with attention-deficit hyperactivity disorder: Evidence from two birth cohorts. Archives of General Psychiatry, 63:462-469.

Miller-Butterworth, C., J. Kaplan, J. Shaffer, B. Devlin, S. Manuck, \& R. Ferrell (2008). Sequence variation in the primate dopamine transporter gene and its relationship to social dominance. Molecular Biology and Evolution, 25:18-28.

Moffitt, T. (2005). The new look of behavioral genetics in developmental psychopathology: Gene-environment interplay in antisocial behavior. Psychological Bulletin, 131:533-554.

Moffitt, T. D. Lynam, \& P.Silva (1994). Neuropsychological tests predicting persistent male delinquency. Criminology, 32:277-300.

Ortiz, J. \& A. Raine (2004). Heart rate level and antisocial behavior in children and adolescents: A meta-analysis. Journal of the American Academy of Child and Adolescent Psychiatry, 43:154-162.

Plomin, R., L. Hill, I. Craig, P. McGuffin, S. Purcell, P. Sham, D. Lubinski, L. Thompson, P. Fisher, D. Turic \& M. Owen (2001). A genome-wide scan of 1842 DNA markers for allelic associations with general cognitive ability: A five-stage design using DNA pooling and extreme selected groups. Behavior Genetics, 31:497-509. 
NOTICE: This is the author's version of a work accepted for publication by Elsevier. Changes resulting from the publishing process, including peer review, editing, corrections, structural formatting and other quality control mechanisms, may not be reflected in this document. Changes may have been made to this work since it was submitted for publication. The definitive version has been published in Criminal Justice, Volume 39, Issue 1, 2011, DOI: 10.1016/i.jcrimius.2010.11.001

Posthumus, J., K. Böcker, M. Raaijmakers, H. Van Engeland \& W. Matthys (2009). Heart rate and skin conductance in four-year-old children with aggressive behavior. Biological Psychology 82:164-168.

Pratt, T., F. Cullen, K.. Blevins \& L.Unnever (2002), The relationship of attention deficit hyperactivity disorder to crime and delinquency: A meta-analysis, International Journal of Police Science and Management, 4:344360

Romaine, C. \& C. Reynolds (2005). A model of the development of frontal lobe functioning: Findings from a metaanalysis. Applied Neuropsychology, 12:190-201.

Rösler, M., W. Retz, P. Retz, G. Hengesch, M. Scneider, \& T. Supprian (2004). Prevalence of attention deficithyperactivity disorder and comorbid disorders in young male prison inmates, European Archives of Psychiatry Clinical Neuroscience, 254:365-371.

Scarpa, A. \& A. Raine (2003). The psychophysiology of antisocial behavior: Interactions with environmental experiences. In Walsh, A. \& L. Ellis (Eds.). Biosocial criminology: Challenging environmentalism's supremacy, pp. 209-226. Hauppauge, NY: Nova Science.

Sergeant, J., H. Geurts, S. Huijbregts, A. Scheres, \& J. Ooserlan (2003). The top and bottom of ADHD: A neuropsychological perspective. Neuroscience and Biobehavioral Reviews, 27:583-592.

Sowell, E., P. Thompson, \& A. Toga (2004). Mapping Changes in the Human Cortex throughout the Span of Life. Neuroscientist, 10:372-392

Thornberry, T., D. Huizinga, \& R. Loeber (2004). The causes and correlates studies: Findings and policy implication. Juvenile Justice, 9:3-19.

Toplak, M., L Connors, J Shuster, B Knezevic, \& S. Parks (2008). Review of cognitive, cognitive-behavioral, and neural-based interventions for Attention-Deficit/Hyperactivity Disorder (ADHD). Clinical Psychology Review, 28: 801-823.

Tripp, G. \& J. Wickens (2009). Neurobiology of ADHD. Neuropharmacology 57:579-589.

Unnever, J., F. Cullen, \& T. Pratt (2003). Parental management, ADHD, and delinquent involvement: Reassessing Gottfredson and Hirschi's general theory. Justice Quarterly, 20: 471 - 500.

Valera, E. S. Faraone, \& K. Murray, L. Seidman (2007). Meta-analysis of structural imaging findings in attentiondeficit/hyperactivity disorder. Biological Psychiatry, 61:1361-1369.

Vaughn, M., M. Delisi, K. Beaver \& J. Wright (2009). DAT1 and 5HTT are associated with pathological criminal behavior in a nationally representative sample of youth. Criminal Justice and Behavior, 36:1113.-1124.

Young, S., G. Gudjonsson, J. Wells, P. Asherson, D. Theobald, B. Oliver, C. Scott \& A. Mooney (2009). Attention deficit hyperactivity disorder and critical incidents in a Scottish prison population. Personality and Individual Differences, 46:265-269.

Walsh, A. (2009). Biology and Criminology: The biosocial synthesis. New York: Routledge.

Wallis D, H. Russell \& M. Muenke (2008). Review: Genetics of attention deficit/hyperactivity disorder. Journal of Pediatric Psychology, 33:8:6-12.

Waschbusch, D., W. Pelham Jr., J.Jennings, A. Greiner, R. Tarter, \& H. Moss (2002). Reactive aggression in boys with disruptive behavior disorders: behavior, physiology, and affect Journal of Abnormal Child Psychology, 30: 641-656.

Williams, J. \& E. Taylor (2006). The evolution of hyperactivity, impulsivity and Cognitive diversity. Journal of the Royal Society Interface, 3:399-413.

Willoughby, M. (2003). Developmental course of ADHD symptomology during the transition from childhood to adolescence: A review with recommendations. Journal of Child Psychology and Psychiatry, 43:609-621.

Wright, J. \& D. Boisvert (2009). What biosocial criminology offers criminology. Criminal Justice and Behavior, 36:1228-1240. 
NOTICE: This is the author's version of a work accepted for publication by Elsevier. Changes resulting from the publishing process, including peer review, editing, corrections, structural formatting and other quality control mechanisms, may not be reflected in this document. Changes may have been made to this work since it was submitted for publication. The definitive version has been published in Criminal Justice, Volume 39, Issue 1, 2011, DOI: 10.1016/i.jcrimius.2010.11.001

\section{Figure 1 Three Pathways to Boys' Delinquency}

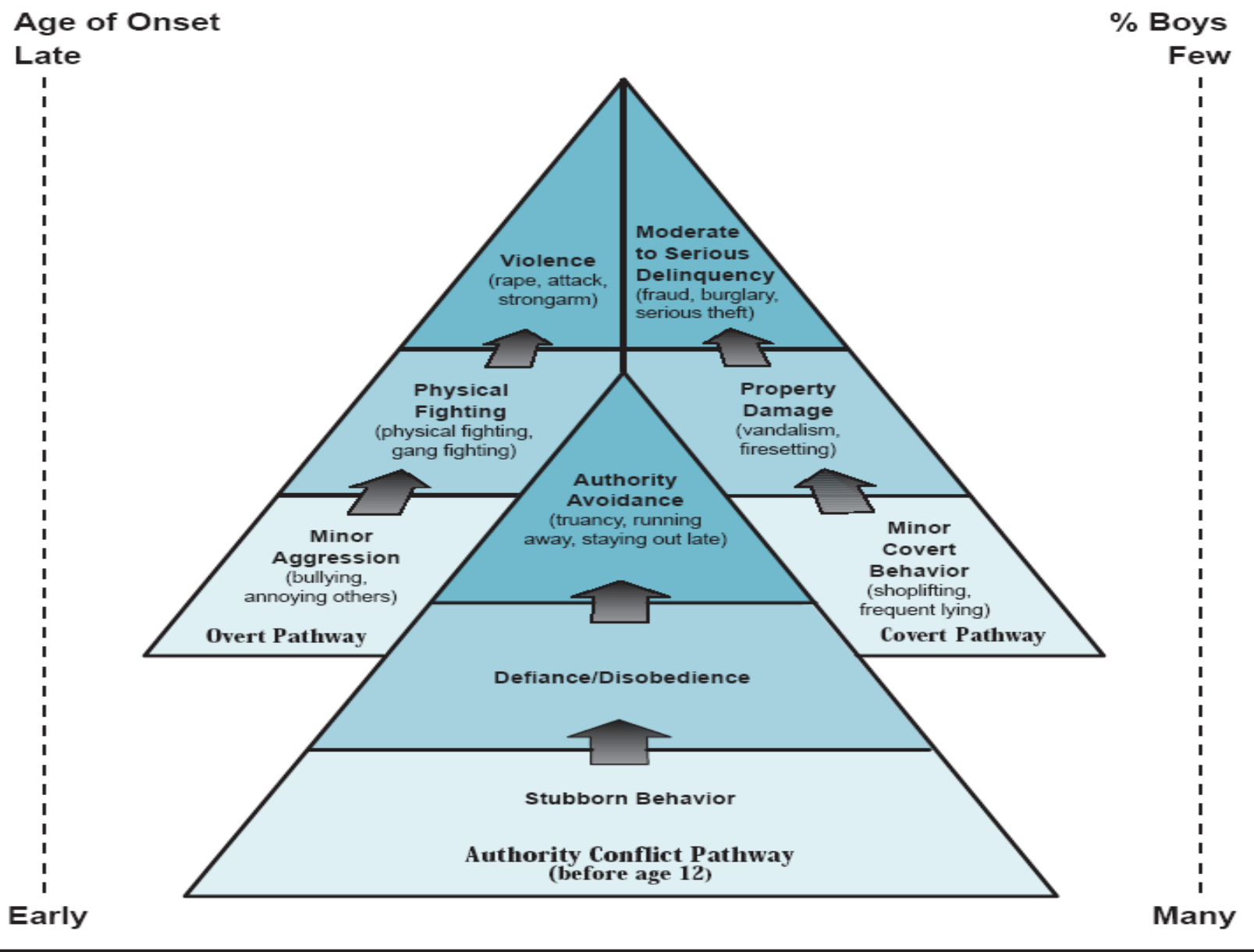

Source: Thornberry, Huizinga, \& Loeber, 2004. U.S. Department of Justice: Juvenile Justice 